УДК 632.112:582.683.2

ФОРМИРОВАНИЕ СТРУКТУРНЫХ ЭЛЕМЕНТОВ

ПРОДУКТИВНОСТИ ЗЛАКОВЫХ И КАПУСТНЫХ КУЛЬТУР ПРИ ИСПОЛЬЗОВАНИИ РИЗОБАКТЕРИЙ

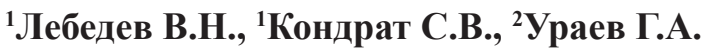 \\ ${ }^{1}$ ФГБОУ ВО «Российский государственный педагогический университет \\ им. А.И. Гериена», Санкт-Петербург, е-mail: antares-80@yandex.ru; \\ ${ }^{2}$ ФББОУ ВО «Петербургский государственный университет путей сообщения \\ Императора Александра I», Санкт-Петербург, e-mail: uraev.ga@yandex.ru
}

В статье обсуждаются результаты проведенных вегетационных опытов по предпосевной инокуляции семян полбы (Triticum dicoccum subsp. asiaticum Vavilov) сорта (к-33226) и горчицы белой (Sinapis alba L.) сорта Рапсодия (к-4278) ассоциативными ризобактериальными препаратами (Агрофилом, Мизорином, Флавобактерином, Псевдомонасом). В работе отмечается, что у полбы и горчицы повышается площадь листовой поверхности, число боковых побегов, число плодов (колосков и стручков), число семян и их масса. Кроме того, выявлено, что боковые побеги у обеих культур вносят вклад в формирование структурных элементов продуктивности. Особенно интенсивно это происходит у полбы. Это может быть связано с тем, что у злаков боковые побеги кущения создают габитус растения и являются фактором регулирования густоты стеблестоя, обеспечивающего продуктивное свойство культуры. Наиболее эффективными бактериальными препаратами для полбы являются Мизорин (Arthrobacter mysorens, штамм 7) и Агрофил (Agrobacterium radiobacter, штамм 10), а для горчицы белой - Мизорин и Флавобактерин (Flavobacterium sp., штамм 30). Выявленная отзывчивость исследованных сортов растений на данные ассоциативные ризобактериальные штаммы наблюдалась по всем изученным нами параметрам продуктивности растений. Проведенная оценка изменения доходов аграрного предприятия от ризобактериальных штаммов на формирование продуктивности зерен полбы и семян горчицы белой. Применение ризобактериальных штаммов позволяет повысить эффект в интервалах 106-114\% от контроля при инокуляции семян полбы и 140-180\% от контроля при инокуляции семян горчицы белой. Наиболее значимый экономический эффект отмечен при инокуляции семян полбы Агрофилом (114\%) и горчицы белой Мизорином (180\%).

Ключевые слова: инокуляция, продуктивность, минеральное питание, структурные элементы продуктивности, ассоциативные ризобактерии, боковые побеги, экономический эффект

\title{
THE EFFECT OF RHIZOBACTERIA ON THE FORMATION OF STRUCTURAL ELEMENTS OF PRODUCTIVITY OF SPELT AND WHITE MUSTARD
}

\author{
${ }^{1}$ Lebedev V.N., ${ }^{1}$ Kondrat S.V., ${ }^{2}$ Uraev G.A.
}

${ }^{1}$ Herzen State Pedagogical University of Russia, Saint Petersburg, e-mail: antares-80@yandex.ru; ${ }^{2}$ Emperor Alexander I St. Petersburg State Transport University, Sankt-Petersburg, e-mail: uraev.ga@yandex.ru

The article discusses the results of pots experiments on pre-inoculation of spelt seeds (Triticum dicoccum subsp. asiaticum Vavilov) var. (k-33226) and white mustard (Sinapis alba L.) of the Rapsodiya / Rhapsody var. (k-4278) with associated rhizobacterial preparations (Agrofil, Mizorin, Flavobacterin, Pseudomonas). The paper notes that spelt and mustard increase the leaf surface area of the leaves, the number of lateral shoots, the number of spikelets and pods, the number of seeds and their weight. In addition, it was found that the lateral shoots of both crops contribute to the formation of structural elements of productivity. This is especially intense in spelt than in mustard. This may be due to the fact that in cereals, the lateral shoots of tillering create the habitus (appearance) of the plant and are a factor in regulating the density of the stem, which provides a productive property of the crop. The most effective bacterial preparations for spelt are Mizorin (Arthrobacter mysorens, strain 7) and Agrophil (Agrobacterium radiobacter, strain 10), and in white mustard Mizorin and Flavobacterin (Flavobacterium sp., strain 30). The revealed responsiveness of the studied plant varieties to these associative rhizobacterial strains was observed for all the parameters of plant productivity. The conducted assessment of the change in the income of an agricultural enterprise from rhizobacterial strains on the formation of productivity of spelt grains and white mustard seeds. The most significant economic effect was observed when inoculating spelt seeds with Agrophil (114\%) and white mustard with Mizorin (180\%).

Keywords: inoculation, productivity, mineral nutrition, structural elements of productivity, associative rhizobacteria, lateral shoots, economic effect

Современное агарное производство в последние годы отличается нарастающими темпами производства и применения бактериальных препаратов на основе ассоциативных ризобактериальных штаммов $[1,2]$. Во многом это определяется интенсификацией земледелия, его экологизацией и доступностью бактериальных препаратов ввиду большого количества их производителей. Ризобактериальные штаммы способны, благодаря выделению биологически активных соединений стимулировать рост и развитие, улучшая минеральное питание растений. Однако использование ассоци- 
ативных ризобактерий может повышать продуктивность сельскохозяйственных культур только при определенных условиях, поскольку отзывчивость представителей даже одного вида, но разного сорта может существенно отличаться [3]. Поэтому всегда необходим тщательный подбор штамма в основе определенного биопрепарата для создания эффективного комплекса «бактерия - растение».

Известно, что наиболее мощная донорно-акцепторная система развита у разновидностей пшеницы, у которых аттрагирующая зона представлена главным колосом, а в качестве донорных структур выступают листья разных ярусов, последовательно включающиеся в обеспечение акцептоpa $[4,5]$. У однолетних полевых капустных растений акцепторная система представлена соцветием главного побега, а к донорным структурам относятся листья и соцветия побегов бокового ветвления [6, 7]. Поэтому согласованная работа этих систем является важным аспектом, определяющим продуктивность биомассы надземных органов и урожайность семян.

Продукционный процесс растений представляет собой интеграцию их физиологических реакций, формирующих урожай. При этом улучшение минерального питания положительно отражается на образовании элементов продуктивности (числа плодов, количества и массы семян). Изучение особенностей формирования колоса у злаков и соцветия у однолетних капустных растений необходимо для характеристики продуктивных возможностей данных культур в конкретных почвенно-климатических условиях, а также прогнозирования и моделирования урожайных данных.

В этой связи цель нашей работы заключалась в определении влияния подобранных наиболее эффективных ризобактериальных штаммов на формирование элементов продуктивности полбы и горчицы белой.

\section{Материалы и методы исследования}

Работа проводилась по стандартной методике [8] в условиях вегетационных опытов с полбяной пшеницей (Triticum dicoccum subsp. asiaticum convar. transcaucasicum Vavilov) образец varietes aeruginosum (к-33226) и горчицей белой (Sinapis alba L.) образец сорта Рапсодия (к-4278) на территории биостанции РГПУ им. А.И. Герцена. Данные культуры считаются малораспространенными для РФ, вопреки перспектив- ности продукционного потенциала, которая отмечается в ряде исследований $[9,10]$.

Растения выращивались в вегетационном домике при естественном освещении и искусственном поливе. В пластмассовые вегетационные сосуды набивалось по 5 кг почвы. В каждый сосуд высевалось по 15 семян, после появления всходов количество проростков выравнивалось. Повторность опыта четырехкратная. Почва, используемая в эксперименте, супесчаная дерново-слабоподзолистая с реакцией среды $\mathrm{pH}_{\mathrm{KCl}}-5,7$ - близкой к нейтральной, со средней степенью окультуренности. По А.Т. Кирсанову определено содержание в ней подвижных форм фосфора (155 мг/кг), калия (120 мг/кг). Для гарантированного создания ассоциативного комплекса «растение - бактерия» перед посевом в почву каждого сосуда в качестве общего минерального фона вносилось комплексное удобрение азофоска из расчета $\mathrm{N}_{0,1} \mathrm{P}_{0,1} \mathrm{~K}_{0,1}$ д.в. на каждый кг почвы.

Инокуляция семенного материала осуществлялась перед посевом в сосуды согласно рекомендациям [10], разработанным ранее непосредственным их изготовителем-лабораторией экологии ассоциативных и симбиотических ризобактерий ВНИИСХМ. В работе использовались: Агрофил (Agrobacterium radiobacter, штамм 10), Мизорин (Arthrobacter mysorens, штамм 7), Флавобактерин (Flavobacterium sp., штамм 30) и Псевдомонас (Pseudomonas fluorescens, штамм ПГ-5). Отбор данных препаратов был сделан на основе ранее проведенных исследований, доказавших свое положительное влияние на отдельные физиологические процессы других сортов, изучаемых культур [1-3].

Изучение морфометрических параметров, вносящих вклад в структуру урожая, осуществлялось у полбяной пшеницы в фазу восковой спелости зерновок, а у горчицы белой - в период зрелости стручков.

Кроме того, практический интерес для нас также представляла оценка изменения дохода аграрного предприятия от процесса предпосевной инокуляции семян полбы и горчицы белой ризобактериями по сравнению с контролем [11]. Заметим, что понятия «экономический эффект» и «экономическая эффективность» связаны между собой. Они относятся к ключевым экономическим категориям и позволяют делать оценку отдачи от применяемой технологии. Экономический эффект характеризует полезный результат от реализации мероприятия или 
мероприятий, оцениваемый либо в форме дополнительного дохода, либо в стоимостной оценке экономии ресурса (ресурсов) по центрам затрат аграрного предприятия.

\section{Результаты исследования и их обсуждение}

Результаты вегетационных опытов показали влияние ризобактериальных препаратов на ассимиляционные органы растений. Площадь листьев обеих культур возрастала в опытных вариантах, но отличалась в зависимости от использованного биопрепарата (табл. 1). Листовая поверхность полбы наиболее существенно отличалась при использовании Мизорина $(167 \%)$ и Агрофила $(144 \%)$, а горчицы - Мизорина (133\%) и Флавбактерина (128\%). в общую урожайность составляет не менее трети, а образцы некустящихся форм пшеницы и неветвящихся сортов горчицы дают на $30 \%$ меньше урожая. При этом у горчицы белой наличие боковых побегов не позволяет растению «перескакивать» фазы развития [5]. Кроме того [9, 13], для таких растений отмечены компактность расположения стручков и снижение ярусности посева, что позволяет снизить потери урожая при уборке.

Таким образом, нельзя однозначно говорить о негативной роли боковых побегов в структуре урожая, а правильную оценку их вклада в продуктивность следует рассматривать применительно к конкретным почвенно-климатическим условиям. Урожайность колоса полбы (или стебля гор-

Влияние бактериальных препаратов на площадь листьев (см²/раст.) и число боковых побегов (шт/раст.) полбы и горчицы белой

\begin{tabular}{|c|c|c|c|c|c|c|c|c|}
\hline \multirow[t]{3}{*}{ Вариант } & \multicolumn{4}{|c|}{ Полба } & \multicolumn{4}{|c|}{ Горчица белая } \\
\hline & \multicolumn{2}{|c|}{ Площадь листьев } & \multicolumn{2}{|c|}{$\begin{array}{c}\text { Число боковых } \\
\text { побегов }\end{array}$} & \multicolumn{2}{|c|}{ Площадь листьев } & \multicolumn{2}{|c|}{$\begin{array}{c}\text { Число боковых } \\
\text { побегов }\end{array}$} \\
\hline & $\mathrm{cm}^{2} /$ раст. & $\%$ & шт/раст. & $\%$ & $\mathrm{~cm}^{2} /$ pact. & $\%$ & шт/раст. & $\%$ \\
\hline Контроль & 729,2 & 100 & 11 & 100 & 64,4 & 100 & 8,5 & 100 \\
\hline Агрофил & 1054,0 & 144 & 12 & 109 & 70,4 & 109 & 8,7 & 102 \\
\hline Мизорин & 1221,5 & 167 & 12 & 109 & 85,5 & 133 & 10,0 & 118 \\
\hline Флавобактерин & 778,1 & 107 & 13 & 118 & 82,5 & 128 & 9,0 & 106 \\
\hline Псевдомонас & 757,5 & 104 & 13 & 118 & 73,4 & 114 & 8,5 & 100 \\
\hline $\mathrm{HCP}_{0,05}$ & 40,4 & - & 0,5 & - & 4,4 & - & 0,3 & - \\
\hline
\end{tabular}

Кроме того, отмечено положительное влияние процесса инокуляции семян на формирование боковых побегов. Особенно интенсивно это наблюдалась у полбяной пшеницы при обработке семян Флавобактерином и Псевдомонасом, а также у горчицы в варианте с Мизорином. Во всех случаях увеличение количества побегов кущения происходило на $18 \%$.

Известно [12], что побеги кущения злаков и боковые побеги однолетних кормовых трав определяют важное продуктивное свойство - густоту стеблестоя. При этом в научной литературе имеются разные представления о физиологических связях между побегами и о вкладе боковых побегов в урожай. Существует точка зрения [3], что боковые побеги задерживают формирование урожая главного побега и отличаются низким продуктивным потенциалом. Другие исследования [2] подчеркивают, что вклад боковых побегов чицы) слагается из трех количественных признаков: числа колосков (или стручков), числа зерен (или числа семян) и массы зерна (или семян). Поэтому практический интерес представлял анализ развития плодов на главном и боковых побегах.

Наиболее стабильными показателями урожайности являются количество колосков в колосе злаков и число стручков в соцветии капустных. Эти показатели в меньшей степени подвержены серьёзным количественным изменениям, хотя тесно связаны с внешними условиями своего формирования $[9,14]$. Дефицит света, тепла, питательных веществ и влаги приводит к нарушению прямой зависимости урожая от числа колосков или стручков.

Обработка семян полбы ассоциативными ризобактериями повышала число колосков в колосе как на главном побеге (до $13 \%$ ), так и на боковых (до $63 \%$ ). Наиболее существенно это отмечалось в вари- 
антах с применением Мизорина (табл. 2). Этот же препарат стимулировал образование стручков у горчицы белой на главном (до $81 \%$ ) и боковых (до $82 \%$ ) побегах. Необходимо отметить, что наибольшее количество колосков и стручков формировалась на главном побеге. Наибольший вклад в процесс формирования колосков боковые побеги вносят у полбы, где их доля колеблется в пределах 36-45\%, в сравнении с горчицей (33-35\%). Это указывает на большую продуктивную ценность главного стебля (побега) по отношению к побегам второго, третьего и последующего порядков, вне зависимости от вида сельскохозяйственного растения [15].

В опытных вариантах нашего исследования показано (табл. 3) увеличение числа зерен в колосе полбы и количества семян в стручках горчицы, относительно неинокулированных вариантов (контроля). Наибольший эффект наблюдался в опытах с применением Мизорина. В этом вариан- те озерненность колоса полбы возрастала на $7 \%$ (главные побеги) и на $25 \%$ (боковые побеги). При этом увеличение обсемененности стручков горчицы белой на одно растение составляло около $80 \%$ независимо от порядка побега. Этот показатель достигался путем изменения числа стручков, а не за счет возрастания количества семян в плодах, поскольку обсемененность стручков является наиболее стабильным показателем, чем озерненность колоса [4].

Следует отметить, что участие боковых побегов в формировании общей озерненности растений полбы составляло 38-70\%, а в обсемененности горчицы - 34-38\%. Этот показатель был максимален при инокуляции семян Мизорином (полба) и Псевдомонасом (горчица). Подобное различие указывает на более функциональный вклад побегов кущения злаковой культуры при обработке семян ассоциативными штаммами ризобактерий, по сравнению с горчицей белой.

Влияние бактериальных препаратов на число колосков полбы

Таблица 2 и число стручков горчицы белой, шт/раст.

\begin{tabular}{|l|c|c|c|c|c|c|c|c|}
\hline \multirow{3}{*}{ Вариант } & \multicolumn{4}{|c|}{ Полба } & \multicolumn{4}{c|}{ Горчица белая } \\
\cline { 2 - 10 } & \multicolumn{3}{|c|}{ Число колосков } & \multicolumn{4}{c|}{ Число стручков } \\
\cline { 2 - 10 } & Главный побег & Боковые побеги & Главный побег & \multicolumn{2}{|c|}{ Боковые побеги } \\
\cline { 2 - 10 } & шт/раст. & $\%$ & шт/раст. & $\%$ & шт/раст. & $\%$ & шт/раст. & $\%$ \\
\hline Контроль & 91 & 100 & 51 & 100 & 8,2 & 100 & 4,1 & 100 \\
\hline Агрофил & 103 & 113 & 66 & 129 & 10,1 & 124 & 5,0 & 123 \\
\hline Мизорин & 103 & 113 & 83 & 163 & 14,8 & 181 & 7,4 & 182 \\
\hline Флавобактерин & 92 & 101 & 52 & 102 & 13,9 & 170 & 6,9 & 169 \\
\hline Псевдомонас & 93 & 102 & 52 & 102 & 12,2 & 149 & 6,6 & 161 \\
\hline НСР & 5,0 & - & 7,3 & - & 3,6 & - & 2,5 & - \\
\hline
\end{tabular}

Влияние бактериальных препаратов на число зерен полбы

Таблица 3 и число семян горчицы белой, шт/раст.

\begin{tabular}{|l|c|c|c|c|c|c|c|c|}
\hline \multirow{3}{*}{ Вариант } & \multicolumn{4}{|c|}{ Полба } & \multicolumn{4}{c|}{ Горчица белая } \\
\cline { 2 - 10 } & \multicolumn{4}{|c|}{ Число зерен } & \multicolumn{4}{c|}{ Число семян } \\
\cline { 2 - 9 } & Главный побег & Боковые побеги & \multicolumn{2}{|c|}{ Главный побег } & \multicolumn{2}{c|}{ Боковые побеги } \\
\cline { 2 - 9 } & шт/раст. & $\%$ & шт/раст. & $\%$ & шт/раст. & $\%$ & шт/раст. & $\%$ \\
\hline Контроль & 169 & 100 & 105 & 100 & 320 & 100 & 172 & 100 \\
\hline Агрофил & 172 & 101 & 105 & 103 & 399 & 124 & 205 & 119 \\
\hline Мизорин & 181 & 107 & 127 & 125 & 578 & 181 & 310 & 180 \\
\hline Флавобактерин & 173 & 103 & 106 & 103 & 549 & 172 & 283 & 165 \\
\hline Псевдомонас & 162 & 96 & 102 & 97 & 468 & 146 & 287 & 167 \\
\hline НСР $_{0,05}$ & 16,0 & - & 13,8 & - & 24,3 & - & 12,1 & - \\
\hline
\end{tabular}


В исследовании выявлено положительное влияние бактериальных препаратов на урожайную массу зерен полбы и семян горчицы (табл. 4). Данные показатели зависят не только от сортовых особенностей, но и от минерального питания. Они формируются в период образования и закладки, зачаточных стручка и колоса (III и IV этапы органогенеза), а также в период завершения формирования семени (X и XI этапы органогенеза) $[4,5,8]$. В отношении полбы наиболее эффективным препаратом, который в целом увеличивал массу зерен на 14 \%, оказался Агрофил. Для горчицы такими препаратами оказались Мизорин и Флавобактерин, где общая масса семян составляла $180 \%$ и $166 \%$ относительно контроля. Эти же ризобактериальные штаммы способствовали более высокой продуктивности как главного, так и боковых побегов изученных нами растений.

Анализ результата вклада боковых побегов в общий урожай показал, что у горчицы белой он наиболее существенен и составлял 44-48\% по сравнению с полбой $-27-34 \%$. При этом продуктивность боковых побегов отмечалась при использовании Флавобактерина и Мизорина.

Рассмотренные выше эффекты от процесса предпосевной инокуляции семян полбы и горчицы белой влияют и на экономический эффект аграрного предприятия (рисунок).

Таблица 4

Урожай семян при инокуляции полбы и горчицы ризобактериями, г/сосуд

\begin{tabular}{|l|c|c|c|c|c|c|c|c|}
\hline \multirow{3}{*}{ Вариант } & \multicolumn{4}{|c|}{ Полба } & \multicolumn{4}{c|}{ Горчица белая } \\
\cline { 2 - 9 } & \multicolumn{4}{|c|}{ Масса зерен } & \multicolumn{4}{c|}{ Масса семян } \\
\cline { 2 - 9 } & \multicolumn{2}{|c|}{ Главный побег } & \multicolumn{2}{|c|}{ Боковые побеги } & \multicolumn{2}{|c|}{ Главный побег } & \multicolumn{2}{c|}{ Боковые побеги } \\
\cline { 2 - 9 } & г/сосуд & $\%$ & г/сосуд & $\%$ & Г/сосуд & $\%$ & \multicolumn{1}{c|}{ госуд } & $\%$ \\
\hline Контроль & 7,2 & 100 & 2,7 & 100 & 1,6 & 100 & 1,4 & 100 \\
\hline Агрофил & 8,1 & 113 & 3,2 & 119 & 2,7 & 169 & 2,1 & 150 \\
\hline Мизорин & 7,3 & 101 & 3,2 & 119 & 2,9 & 181 & 2,5 & 179 \\
\hline Флавобактерин & 7,3 & 101 & 3,3 & 122 & 2,6 & 163 & 2,4 & 171 \\
\hline Псевдомонас & 7,4 & 103 & 3,1 & 115 & 2,3 & 144 & 1,9 & 136 \\
\hline НСР $_{0,05}$ & 0,2 & - & 0,2 & - & 0,2 & - & 0,2 & - \\
\hline
\end{tabular}

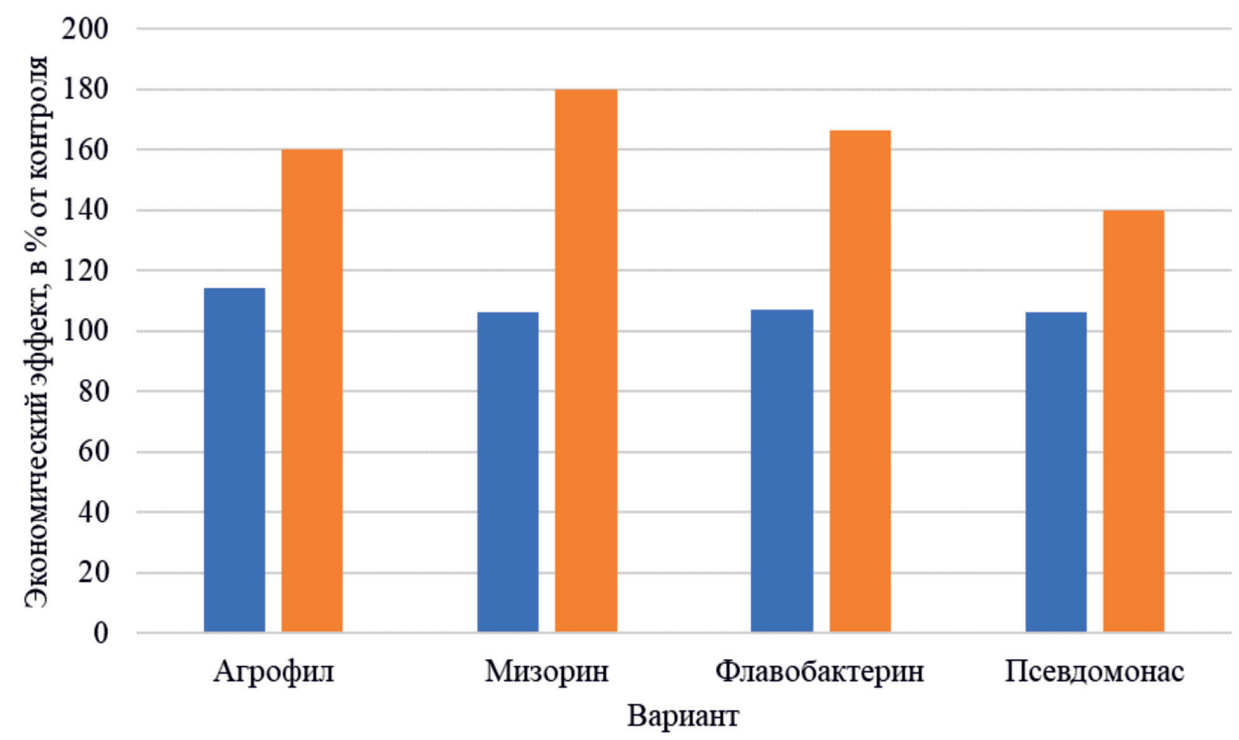

- Полба Горчица белая

Изменение доходов аграрного предприятия от реализаиии семян полбы и горчииь белой (контроль принят за 100\%) 
На рисунке показана оценка изменения доходов аграрного предприятия от ризобактериальных штаммов на формирование продуктивности зерен полбы и семян горчицы белой. Применение ризобактериальных штаммов позволяет повысить эффект в интервалах 1,06-1,14 раза (по полбе) и 1,40-1,80 (по горчице белой). Наиболее значимый экономический эффект наблюдается при инокуляции семян полбы Агрофилом $(1,14$ раза) и горчицы белой Мизорином $(1,80$ раза).

\section{Заключение}

Таким образом, результаты вегетационных опытов показали эффективное влияние на продуктивные процессы полбяной пшеницы и горчицы белой. Отобранные штаммы ассоциативных ризобактерий повышали ассимиляционную поверхность листьев (полбы - на 4-67\%; горчицы - на 9-33\%) и стимулировали образование боковых побегов (полбы - на 9-18\%; горчицы на $2-18 \%$ ) у обоих видов растений. Кроме того, было отмечено, что инокулированные варианты растений формировали большее число плодов и семян, а также положительно отличались в отношении урожая семенной массы (полба - $114 \%$; горчица - 166$180 \%$ относительно контроля). Наиболее эффективным биопрепаратом по совокупности рассмотренных параметров, в отношении обеих культур оказался Мизорин (Arthrobacter mysorens, штамм 7). Однако установлено, что для полбы еще одним эффективным бактериальным препаратом является Агрофил (Agrobacterium radiobacter, штамм 10), а для горчицы - Флавобактерин (Flavobacterium sp., штамм 30).

В работе также отмечена положительная роль боковых побегов в продукционных процессах. Наиболее существенное значение урожайности таких побегов характерно для полбы (27-34\% от общей урожайности) как злаковой культуры, регулирующей густоту стеблестоя, по сравнению с горчицей белой (44-48\% от общей урожайности). Кроме того, установлен экономический эффект от применения бактериальных препаратов для повышения семенной продуктивности исследованных нами растений. Наиболее значимый экономический эффект отмечен при инокуляции семян полбы Агрофилом $(114 \%)$ и горчицы белой Мизорином $(180 \%)$.

\section{Список литературы / References}

1. Акманаев Э.Д. Инновационные технологии в агробизнесе: учеб. пособие / Под общ. ред. Ю.Н. Зубарева, С.Л.
Елисеева, Е.А. Ренева; М-во с.-х. РФ, ФГБОУ ВПО «Пермская ГСХА». Пермь: ФГБОУ ВПО «Пермская ГСХА», 2012. $335 \mathrm{c}$.

Akmanaev E.D. Innovative technologies in agribusiness: textbook. stipend / pod obshch. red. Yu.N. Zubareva, S.L. Eliseeva, E.A. Reneva; M-vo s.-h. RF, FGBOU VPO Permskaya GSKHA. Perm': FGBOU VPO Permskaya GSKHA, 2012. 335 p. (in Russian).

2. Fatih C., Murat E., Mehmet S., Arzu C. The role of beneficial microorganisms in the protection of plants growing in natural landscape areas. Siirt. 2017. P. 427-442.

3. Лебедев В.Н. Реализация продуктивного потенциала растений семейства Brassicaceae при инокуляции семян ассоциативными ризобактериями. Глава 3 // Наука сегодня: теория, практика, инновации: многотомная коллективная монография. В 9 т. Т. 6. Ростов-на-Дону: Изд-во Международного исследовательского центра «Научное сотрудничество», 2014. C. 56-77.

Lebedev V.N. Realization of the productive potential of plants of the Brassicaceae family when inoculating seeds with associative rhizobacteria. Chapter 3 // Nauka segodnya: teoriya, praktika, innovacii: mnogotomnaya kollektivnaya monografiya. V 9 t. T. 6. Rostov-na-Donu: Izd-vo Mezhdunarodnogo issledovatel'skogo centra «Nauchnoe sotrudnichestvo», 2014. P. 56-77 (in Russian).

4. Степанов С.А., Сигнаевский В.Д., Касаткин М.Ю., Ивлева М.В. Формирование элементов продуктивности колоса яровой мягкой пшеницы // Известия Саратовского университета. Новая серия. Серия: Химия. Биология. Экология. 2013. T. 13. № 1. C. $65-70$.

Stepanov S.A., Signaevskiy V.D., Kasatkin M.Yu., Ivleva M.V. Formation of elements of productivity of an ear of spring soft wheat // Izvestiya Saratovskogo universiteta. Novaya seriya. Seriya: Himiya. Biologiya. Ekologiya. 2013. T. 13. № 1. P. 65-70 (in Russian).

5. Горюнов А.А. Формирование элементов продуктивности колоса яровой твердой пшеницы: автореф. дис. ... канд. биол. наук. Саратов, 2012. 19 с.

Goryunov A.A. Formation of elements of productivity of an ear of spring durum wheat: avtoref. dis. ... kand. biol. nauk. Saratov, 2012. 19 p. (in Russian).

6. Панасюга А.П., Саскевич П.А., Кажарский В.Р. Влияние морфорегуляторов на продуктивность горчицы белой // Вестник БГСХА. 2017. № 1. С. 33-37.

Panasyuga A.P., Saskevich P.A., Kazharskiy V.R. The influence of morphoregulators on the productivity of white mustard // Vestnik BGSKHA. 2017. № 1. P. 33-37 (in Russian).

7. Петров С.В. Агробиологические основы формирования урожая яровой пшеницы полбы в Предкамье Республики Татарстан: автореф. дис. ... канд. сельхоз. наук. Пенза, 2015. 19 c.

Petrov S.V. Agrobiological bases of the formation of the spring wheat spelt crop in the Kama region of the Republic of Tatarstan: avtoref. dis. ... kand. s.-h. nauk. Penza, 2015. 19 p. (in Russian).

8. Воробейков Г.А., Бредихин В.Н., Павлова Т.К., Лебедев В.Н., Кондрат С.В., Чернявская И.В., Макаров П.Н. Учебная полевая практика по физиологии растений: учебное пособие для студентов биологических специальностей / Под ред. профессора Г.А. Воробейкова. СПб.: Изд-во РГПУ им. А.И. Герцена, 2015. 128 с.

Vorobeykov G.A., Bredikhin V.N., Pavlova T.K., Lebedev V.N., Kondrat S.V., Chernyavskaya I.V., Makarov P.N. Educational field practice in plant physiology: a textbook for students of biological specialties / Pod red. professora G.A. Vorobeykova. SPb.: Izd-vo RGPU im. A.I. Gercena, 2015. 128 p. (in Russian).

9. Велкова Н.И., Наумкин В.П. Факторы, влияющие на урожайность горчицы белой // Вестник научных конференций. 2016. № 11-5 (15). С. 48-50.

Velkova N.I., Naumkin V.P. Factors affecting the yield of white mustard// Vestnik nauchnyh konferenciy. 2016. № 11-5 (15). P. 48-50 (in Russian). 
10. Тихонович И.А., Завалин А.А., Благовещенская Г.Г., Кожемяков А.П. Использование биопрепаратов - дополнительный источник элементов питания растений // Плодородие. 2011. № 3 (60). С. 9-13.

Tikhonovich I.A., Zavalin A.A., Blagoveshchenskaya G.G., Kozhemyakov A.P. The use of biological products is an additional source of plant nutrition elements // Plodorodie. 2011. № 3 (60). P. 9-13 (in Russian).

11. Лебедев В.Н., Воробейков Г.А., Ураев Г.А. Повышение продуктивности растений семейства капустных (Brassicaceae Burnett.) при инокуляции семян бактериальными препаратами на основе ассоциативных штаммов Успехи современного естествознания. 2017. № 5. С. 41-45.

Lebedev V.N., Vorobeykov G.A., Uraev G.A. Increasing the productivity of plants of the cabbage family (Brassicaceae Burnett.) when inoculating seeds with bacterial preparations based on associative strains // Uspekhi sovremennogo estestvoznaniya. 2017. № 5. P. 41-45 (in Russian).

12. Шайхутдинов Ф.Ш., Сержанов И.М., Зиннатуллин Д.Х., Асахова В.В. Формирование стеблестоя, рост корневой системы и урожайность агроценоза полбы (Triticum dicoccum Schrank.) в зависимости от агротехнических приемов в условиях Республики Татарстан // Достижения науки и техники АПК. 2019. Т. 33. № 5. С. 21-25.

Shaykhutdinov F.Sh., Serzhanov I.M., Zinnatullin D.Kh., Asahova V.V. The formation of the stem, the growth of the root system and the yield of the agrocenosis of spelt (Triticum di- coccum Schrank.) depending on agrotechnical techniques in the conditions of the Republic of Tatarstan // Dostizheniya nauki i tekhniki APK. 2019. Vol. 33. № 5. P. 21-25 (in Russian).

13. Лебедев В.Н., Ураев Г.А. Перспективность инокуляции семян горчицы белой и сарептской ассоциативными азотфиксирующими штаммами ризобактерий // Пермский аграрный вестник. 2015. № 11. С. 21-25.

Lebedev V.N., Uraev G.A. The prospects of inoculation of white and Sarepta mustard seeds with associative nitrogen-fixing strains of rhizobacteria // Permskij agrarnyj vestnik. 2015. № 11. P. 21-25 (in Russian).

14. Гилев С.Д., Цымбаленко И.Н., Мешкова Н.В., Филиппова Е.А., Козлова Т.А. Урожайность полбы и технологические качества зерна в зависимости от приемов возделывания // Аграрный вестник Урала. 2017. № 5 (159). C. $12-16$.

Gilev S.D., Cymbalenko I.N., Meshkova N.V., Filippova E.A., Kozlova T.A. The yield of spelt and the technological qualities of grain, depending on the methods of cultivation // Agrarnyj vestnik Urala. 2017. № 5 (159). P. 12-16 (in Russian).

15. Leonova I.N., Badaeva E.D., Orlovskaya O.A., Röder M.S., Khotyleva L.V., Salina E.A., Shumny V.K. Comparative characteristic of Triticum aestivum/Triticum durum and Triticum aestivum/Triticum dicoccum hybrid lines by genomic composition and resistance to fungal diseases under different environmental conditions. Russian Journal of Genetics. 2013. Vol. 49. № 11. P. 1112-1118 